\title{
Collaboration among IMIA WG and Special Interest Groups
}

\author{
Hyeoun-Ae Park, VP for WG \& SIGs \\ College of Nursing, Seoul National University, Seoul, South Korea
}

There are 20 IMIA Working and Special Interest Groups (WG/SIGs), which consist of individuals who share common interests in a particular focal field. These individuals collaborate through WG/SIGs. IMIA WGs have collaborated with other associations and societies in the field. For example, the Biomedical Pattern Recognition WG has collaborated with IEEE EMBS (Engineering in Medicine and Biology Society), Primary Health Care Informatics with the Informatics Working Party of WONCA (the World Organization of Family Doctors), and the Standards in Health Care Informatics WG with ISO/TC 215 and CEN TC 251.

IMIA WGs also have collaborated with mirror WGs in the Regional and National Member Societies. For example, the Biomedical Pattern Recognition WG has collaborated with the EFMI Medical Image Processing WG, the Organizational and Social Issues WG with the AMIA People and Organizational Issues WG, the Primary Care Informatics WG with the AMIA Primary Care Informatics WG, the Open Source WG with the EFMI (European Federation for Medical Informatics) Open Source WG, and the Standards in Health Care Informatics WG is collaborating with the APAMI (Asia Pacific Association for Medical Informatics) Standard WG.

Even though there has been collaboration among IMIA WG/SIGs, such as the Technology Assessment \& Quality Development in Health Informatics WG with the Human Factors Engineering WG, the Open Source WG with the Health Informatics for Development WG, and WGs in the Nursing Informatics SIG with corresponding IMIA WGs, it is very limited. As a vice president for WG/SIGs, I would like to identify areas for collaboration among WG/SGIs by reviewing the goals/objectives, scope, and activities of each WG/SIG, and proposing ways to facilitate collaboration among WG/SIGs.

WGs in the Nursing Informatics Special Interest Group with corresponding IMIA WGs have their own WGs, and each WG within the SIG can collaborate with the corre- sponding IMIA WGs. They are the Consumer Health Informatics, Education, Open Source, and Standards WGs

The Health and Medical Informatics Education WG, which is interested in disseminating and exchanging information on Health and Medical Informatics programs and courses, can collaborate with the Health Informatics for Development WG to organize Health and Medical Informatics educational activities in developing regions. This WG can also collaborate with the Health Informatics for Development $\mathrm{WG}$ to find out how health informatics can improve living conditions in developing regions and to implement programs in that direction.

The Human Factors Engineering for Healthcare Informatics WG, dealing with the cognitive aspects of human-computer interaction, can collaborate with the Consumer Health Informatics WG to make computers a welcome partner for both the clinician and the patient in the empowered longitudinal care of the individual. This WG can also collaborate with the Standard WG to create standards for the use of human factor engineering and usability testing in the certification of EHRs.

The Informatics in Genomic Medicine WG can collaborate with the Health Information Systems WG to integrate molecular and genomic information (genetic testing, mutation analysis, gene and protein expression) into health information systems and tools (electronic health records, computerized protocols and clinical guidelines, clinical trials in the context of pharmacogenetics, molecular imaging).

The Intelligent Data Analysis WG can collaborate with the Informatics in Genomic Medicine WG on knowledge-based functional genomics and intelligent data analysis of molecular phenotypes. The Medical Concept Representation WG can collaborate with the Standard WG on classification and nomenclature in health care. The Open Source WG is collaborating with other IMIA Working and Special Interest Groups to explore the appropriate use of free/libre and open source solutions and applications, and to facilitate both the use of other groups' expertise in the areas under consideration, and the input of IMIA views to those other groups' work and discussions.

The Organizational and Social Issues WG can collaborate with Consumer Health Informatics on individual behavioral issues surrounding the introduction and use of informatics applications, and the Human Factor Engineering WG on incorporating human concerns into information technology projects. The Primary Health Care Informatics WG can collaborate with Health Informatics for Development on the progression of primary care informatics in developing countries. Security in Health Information Systems can collaborate with the Health Information Systems WG on the data protection and security of distributed electronic patient records. The Telematics WG, dealing with the integrated use of telecommunications and informatics in healthcare, can collaborate with the Health Information for Development WG because telematics is a way to improve Healthcare in developing countries. This WG can also collaborate with the Biomedical Pattern Recognition WG in Tele-Radiology related activities.

One way to promote collaboration among IMIA WG/SIGs would be to identify areas where collaboration among WG/SIGs is needed and to organize a series of joint meetings of relevant WG/SIGs at an international conference such as the triennial Medinfo conference. Some working groups have already identified areas of collaboration and are planning to organize joint WG meetings during Medinfo 2010. For example, HI4D is planning to have a joint WG meeting with the Open Source WG. As VP for WG/SIG, I would like to organize a WG/SIG chairs meeting to discuss ways to improve collaboration among IMIA WG/SIGs during Medinfo 2010 in Cape Town, as some of the previous VPs for IMIA WG/SIG have done before me. I would like to suggest that the WG/SIGs chairs meeting be held on a regular basis, whether it is offline or online, in order to facilitate collaboration among IMIA WG/SIGs. 


\section{Nursing Informatics (Special Interest Group 1)}

Chair :

Heimar Marin (2009-2012)

Professor, Nursing Informatics Group

Federal University of Sao Paulo

Rua Napoleao de Barros 754

Sao Paulo CEP:04024002 Brazil

Tel: +551150821036

Fax: +55115733371

E-mail:hfmarin@attglobal.net or heimar@denf.epm.br

Vice Chairs:

William TF Goossen - Working Groups (2009-2012)

Director, Results 4 Care b.v.

De Stinse 15

3823 VM Amersfoort

Tel: +31654614458

$\mathrm{Fax}+31332570169$

E-mail:Results4Care@cs.com or williamifgoossen@cs.com

Hyeoun-Ae Park-Membership (2009-2012)

Professor, College of Nursing

Seoul National University

28 Yongon-dong Chongno-gu

Seoul, 110-799 Korea (South)

Tel: +8227408827

Fax: +8227654103

E-mail:hapark@snu.ac.kr

Patrick Weber - Communication (2009-20012)

Nice Computing

Ch de Maillefer 37

CH-1052 Le Mont-sur-Lausanne, Switzerland

Tel: + 41216410420

Fax: +41216410429

Mobile +41792128885

E-mail:patrick.weber@nicecomputing.ch

Lucy Westbrooke - Administration and Finance (2009-2012) Information Management Consultant, Information Management and Technology Service, Auckland District Health Board

Building 10, Greenlane Clinical Centre

Greenlane Rd West, Epsom, Auckland 1051

PO Box 92-189, Auckland 1142

Tel: +64 9) 3074949 ext3467 or 25827

Mobile: +64921938075

Fax: +6496310794

E-mail: lucyw@adhb.govt.nz

Website: http://www.imiani.org

\section{Objectives:}

- Explore the scope of Nursing Informatics and its implications for health policy and information handling activities associated with evidence based nursing practice, nursing management, nursing research, nursing education, standards and patient (or client) decision making and the various relationships with other health informatics entities.

- Identify priorities or gaps and make recommendations for future developments in nursing informatics.

- Support the development of nursing informatics in member countries and promote nursing informatics worldwide.

- Promote linkages and collaborative activities with national and international nursing and health informatics groups and nursing and health care organisations globally.

- Provide, promote and support informatics meetings, conferences, and electronic communication forums to enable opportunities for the sharing of ideas, developments and knowledge.

- Participate in IMIA working groups and special interest groups to present a nursing perspective.

- Develop recommendations, guidelines, tools and courses relating to nursing informatics.

- Encourage the publication and dissemination of research and development materials in the field of nursing informatics

- Support and work with patients, families, communities and societies to adopt and manage informatics approaches to healthcare.

\section{Recent Activities:}

The $10^{\text {th }}$ International Congress on Nursing Informatics, NI 2009 was held in Helsinki, Finland. The theme of the conference was Nursing Informatics - Connecting Health and Humans. More than 500 from more than 35 countries participated in the conference. More than 150 papers and posters were presented.

New executive officers were elected at the IMIA-NI GA held in Helsinki Finland before NI 2009. New chair is Heimar Marin from Brazil and new vice chairs are William Goossen from the Netherlands for working groups, Hyeoun-Ae Park from Korea for membership, Patrick Weber from Switzerland for communication and Lucy Westbrooke from New Zealand for administration/finance. They will serve IMIA-NI until 2012.

NI 2009 Post Congress Conference was held in Vanaja Castle located near the city of Hameenlinna Finland July 1-4, 2009. The theme of the conference was "Personal Health Information Management: Tools and Strategies for Citizen's Engagement. Thirty two experts from more than 15 countries were divided into 7 small groups and worked on different topics around the theme. Topics include Personal Health Information Management System, Usability, Technology, Practice, Consumers, Governance, and Education. The proceedings from this conference will be available sometime in November 2009.

\section{Future Activities:}

NI SIG will host a workshop at Medinfo 2010, 13th International Congress on Medical Informatics to be held in Cape Town, South Africa during 13 - 16 September 2010. NI 2012 will be held in Montreal Canada from June 23 to June 27, 2012 . 


\section{Objectives:}

To promote applications in medicine and biology focusing on methods of pattern recognition and interpretation.

\section{Recent Activities:}

The most prominent activity of WG7 this year was the workshop "Biosignal Processing and Interpretation BSI" at Yale University, Connecticut, from June 23-26, 2009 (http://www.bsi2009.org). The workshop was perfectly organized by Dr. Ki Chon (Chair), SUNY Stony Brook, NY, USA and Dr. Yana Kazuo (Co-Chair), Hosei University, Japan. It took place under the umbrella of IMIA, the International Federation for Medical and Biological Engineering (IFMBE) in collaboration with the IEEE, Engineering in Medicine and Biology Society (EMBS), and the State University of New York at Stony Brook.

More than 100 participants from 14 countries, international leaders in the biosignal field as well as students were discussing the latest advancements in their field for three days. Dr. N. Thakor, John Hopkins University USA, opened the scientific program with a keynote "Taking Neural Signal Processing from Bench to Bedside". Forty four oral contributions and 16 posters were presented and extensively discussed.

The program aimed at exploring the new fields of biosignal interpretation including model based signal analysis, data interpretation and integration, medical decision making, extending the existing signal processing methods and technologies for the effective utilization of biosignals in a practical environment and for a deeper understanding of biological functions from the whole organism, system, to cellular and gene scales.

A selected number of presentations will be published in Methods Information in Medicine and in the International Journal of Bioelectromagnetism.

A welcome reception and a rich banquet provided an excellent opportunity for socializing and meeting good friends. The next workshop will take place in 2012 in Italy, organized by Dr. S. Cerutti and his group.

Furthermore, a considerable number of WG7 members presented recent research at the IEEE EMBS Conference 2009 from September 3-6 in Minneapolis Minnesota as well as at the World Congress on Medical Physics and Biomedical Engineering 2009 from September 7-12 in Munich Germany.

\section{Future Activities:}

The next workshop will take place in 2012 in Italy, organized by Dr. S. Cerutti and his group.

\section{Biomedical Pattern Recognition \\ Chair(2007-2010): \\ Prof. Dr. Harmut Dickhaus \\ University ofHeidelberg \\ Institute for Medical Biomety and Informatics \\ Department of Medical Informatics \\ Im Nevenheimer Feld 305 \\ D-69120 Heidelberg, Germany \\ Tel. : + $49622156-7483$ \\ Fax: + 496221 56-4997 \\ E-mail:hartmut.dickhaus@med.uni-heidelberg.de}




\section{Consumer Health Informatics}

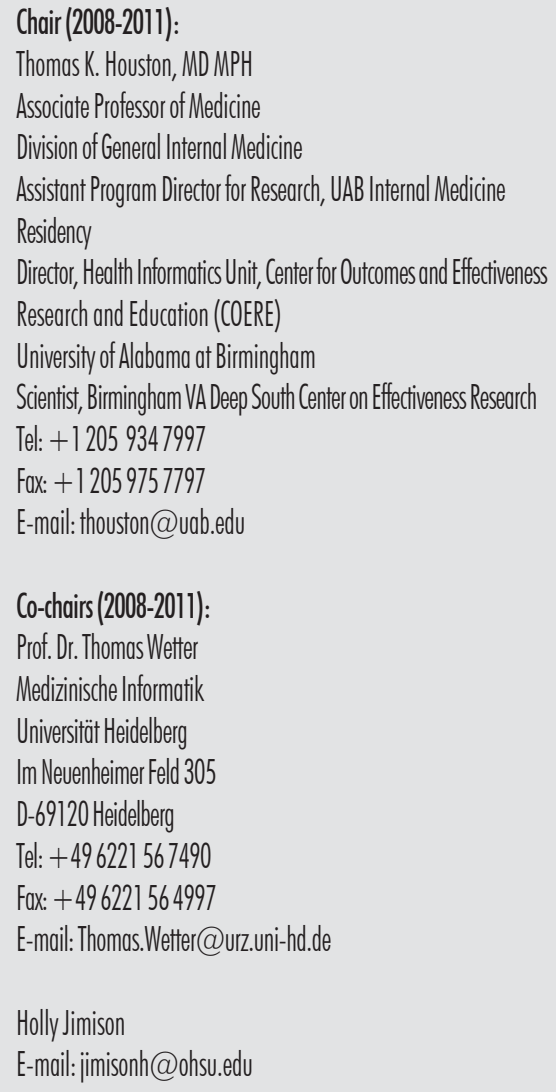

\section{Scope:}

The Consumer Health Informatics Working Group (CHIWG) became an official IMIA Working Group in 2000. The CHIWG is concerned with electronic information related to health care available to the public (e.g. Internet, wireless, standalone electronic media). For its purposes, it defines Consumer Health Informatics as "the use of modern computers and telecommunications to support consumers in obtaining information, analyzing unique health care needs and helping them make decisions about their own health" (U.S. General Accounting Office, 1996, p.1.), in which the consumer interacts with the applications directly with or without the presence of health care professionals. The group's interests focus on, but are not limited to, world wide web sites that offer advice about healthy living, research findings, and recommendations on specific disease conditions, descriptions of products, medications, and self-care health programs available to the public. Issues of concern may be the evaluation of the quality of information, education of the public, ethical issues related to the electronic information, and the effect on a person's health care and relationship with health care providers.

\section{Objitives for the next 3 years:}

The WG hopes to work with the IMIA leadership on strengthening the role of the Working Groups within IMIA. We look forward to greater participation in key IMIA activities, increasing the visibility and impact of CHI WGs in the world.

- Provide greater opportunities to share CHI related information from relevant and accessible sources such as the International Journal of Medical Informatics (IJMIA), and the Journal of Medical Internet Research (JMIR). Emphasis will be given to high-quality studies and randomized trials published in quality journals.

- The group plans to hold a business meeting at Medinfo 2007, and plans a tutorial

- The group will continue to liaise with counterparts in other countries, such as the AMIA WG CHI, EFMI, IMIA's NI-SIG(WG on CHI).

- A priority will be to expand our contacts with CHI interest groups in Asia and Africa.

\section{Recent Activities:}

Thomas K Houston is pro tem chair of the group. Activities of the group include:

1. We had our business meeting at MedInfo in 2007. Attendees for this meeting were attached. At MedInfo, we decided to have the leadership of the group fall to Tom Houston (Chair), and two Co-Chairs (Holly Jimison and Thomas Wetter).

2. We have a facebook group - with 18 current members and ongoing discussions.

3. Several WG members participated in the Medicine 2.0 conference in Toronto (see the associated crowdvine site).

4. Thomas is planning on leading an effort to create a white paper.

5. As per previous emails from Peter, we would request that you put a motion to the IMIA GA that JMIR be endorsed as a official journal of the IMIA CHI WG..

6. Members of the working group have also worked with the U.S. Society of Behavioral Medicine in August, 2008, to submit a panel discussion "Cyberinfrastructure for behavioral informatics" as it is relevant to consumer health informatics

\section{Future Activities:}

Report from pro tem vice-chair of the group (Thomas Wetter) regarding future activities

1 There seems to be an adhoc kind of activity at NLM/Lister Hill associated with the name Keselman about CHI terminology. I suggest that we hook up to this and beyond, to get CHI listed as a MeSH term.

2 More Book Publishers are subscribing to $\mathrm{CHI}$ :

- IGI is publishing one edited by Vance Wilson

- Springer is publishing the one I'm writing.

We might take this opportunity to initiate a CHI competencies gathering activity 


\section{Objectives:}

To bring the small, but rapidly growing, community of dental informaticians around the world into closer contact.

\section{Objectives:}

- To disseminate and exchange information on Health and Medical Informatics (HMI) programs and courses

- To promote the IMIA HMI database of programs and courses on HMI education

- To produce international recommendations on HMI programs and courses

- To support HMI courses and exchange of students and teachers

- To advance the knowledge of:

1. How informatics is taught in the education of health care professionals around the world

2. How in particular health and medical informatics is taught to students of computer science/informatics

3. How it is taught within dedicated curricula in health and medical informatics

\section{Recent Activities:}

William Hersh is the current Chair of the group, starting a second three-year term. John Mantas is the outgoing Co-Chair, while Paula Otero is the incoming Co-Chair. Activities of the group include:

1. Identifying and harmonizing competencies and curricula for health and biomedical informatics, including upcoming workshops in Buenos Aires and updating of the IMIA curriculum recommendations.

2. Improving our Web presence.

3. Participating in our next working group conference in October, 2008.

4. AMIA/IMIA collaboration on both the Rockefeller eHealth initiative and the 2020 initiative

Here is an update with more detail:

1. Identifying and harmonizing competencies and curricula

One of the concerns that many of us have is the development of competencies and curricula for health and biomedical informatics education around the world. There are several existing and planned efforts, particularly in the United States and Europe. It would be nice, where possible, to harmonize these efforts. But short of that, it would still be valuable to inventory them all, especially in some sort of database or wiki.

John Mantas has been leading the effort to update the IMIA curriculum recommendations over the last two years. A near-final version of the draft is out for comment to working group members and will hopefully be approved by the IMIA Board at its upcoming meeting in Hiroshima, Japan in November, 2009.

2. Improving our Web presence

The Web site for our group on the IMIA site is still woefully out of date and there has been no movement on improving methods to update it. We have created our own separate Web presence on a wiki at: http://imiawged.pbwiki.org/

Unfortunately, this site has become out of date as well. A clear need for the group is leadership in enhancing the Web presence.

\section{Dental Informatics}

\section{Chair(2009-2012): \\ Miguel Humberto Torres-Urquidy, DDS MS \\ Post-doctoral Associate, Ctr. for Dental Informatics \\ University of Pittsburgh, USA \\ Tel: +1412648-8611 \\ E-mail:mit7@piit.edu \\ Health and Medical Informatics Education}

\author{
Chair(2006-2009, 2009-2012): \\ Professor William Hersh, MD \\ Department of Medical Informatics and Clinical Epidemiology \\ Oregon Health and Science University \\ 3181 SW Sam Jackson Park Road \\ Portland, Oregon, 97239, USA \\ Tel: +15034944502 \\ Fax: +15034944551 \\ E-mail:hersh@ohsu.edu \\ Co-chairs: \\ Paula Otero, MD (2009-2012) \\ Hospital ltaliano \\ Coordinadora del Area productos Medicos HIBA \\ Departamento de Informacion Hospitalaria HIBA \\ Gascón 450, (1181) Buenos Aires, Argentina \\ Phone: +54-11-42939365 \\ Fox:+54-11-42939365 \\ E-mail: paula.otero@hospitalitaliano.org.ar
}

Professor John Mantas, PhD (2006-2009)

Health Informatics Laboratory

Faculty of Nursing, University of Athens

123 Papadiamantopoulou Street

GR-11527 Athens, Greece

Tel: $+302107461459 / 60$

Fax: +302107461461

E-mail:.imantas@cc.uoa.gr

Websites: hitp://www.imia.org/wgl

http://imiawged.pbwiki.org/ 


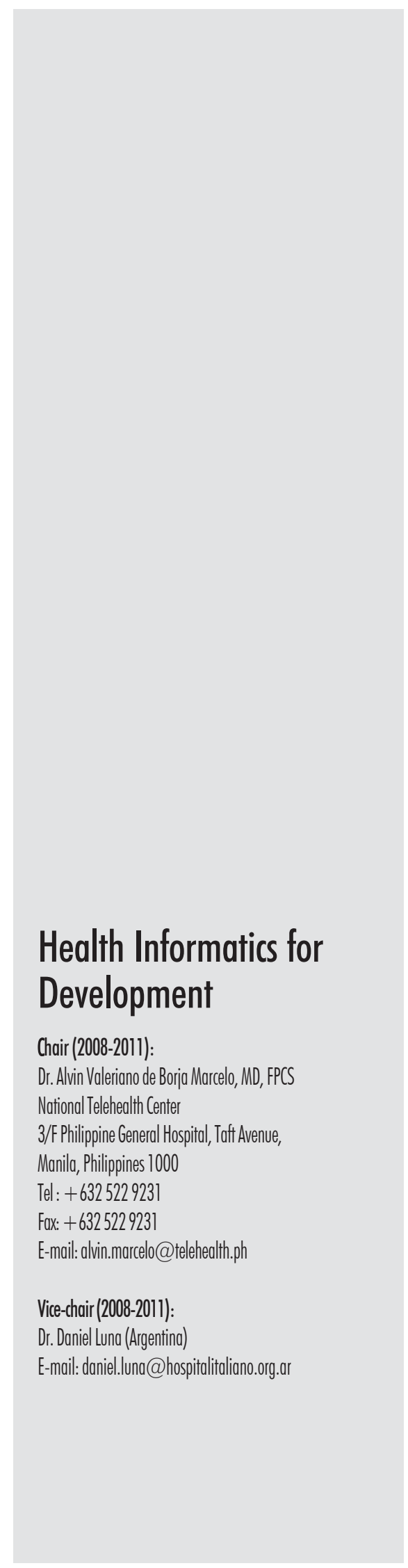

3. Working group conference

A conference of the working group was hosted by the Department of Medical Informatics at Hospital Italiano de Buenos Aires (HIBA) in Buenos Aires, Argentina from 27-28 October 2008. The goal of the conference was to provide both an exposition for identifying and harmonizing competencies and curricula for health and biomedical informatics as well as provide a working meeting for ongoing work of the IMIA Working Group on Health and Medical Informatics Education. The format of the meeting alternated between workshop sessions and paper presentations. There was also be a business meeting for the IMIA Working Group on Education. The archival meeting Web site is at: http://www.hospitalitaliano.org.ar/ imiawged/

A few of the papers from the conference will be published as a special issue in an upcoming issue of Methods of information in Medicine.

4. AMIA/IMIA collaboration on both the Rockefeller eHealth initiative and the AMIA Global Partnership Program

A number of working group members have been active in building capacity and educational opportunities in developing countries. Several working group members took part in the Making the eHealth Connection meeting in July, 2008 in Bellagio, Italy, which was funded by the Rockefeller Foundation. The archival Web site for this meeting is at:

http://www.ehealth-connection.org/

Much of this work continues forward in the AMIA Global Partnership Program, which is funded by a grant from the Gates Foundation. Bill Hersh and Paula Otero head up one of the four subcommittees of the project devoted to Training Approaches and Contents. More information about the GPP project can be found at: http://www.amia.org/GPP

These projects will likely be able to serve as a focus of the working group and a bridge between IMIA and AMIA.

\section{Objectives:}

- To find out how health care informatics could improve live conditions in developing regions and implement programs in that direction.

- Organization of forums to exchange of experiences of colleagues working in the field of health informatics.

- Making a list of the needs and resources in medical informatics for each country.

- Organization of educational activities in developing regions, especially through the implementation of professors' exchange.

- Organizing workshops and seminars with international experts participation

\section{Recent Activities:}

The IMIA WG on Health Informatics for Development (IMIA WG HI4Dev) is now under new management with Dr. Alvin Marcelo (Philippines) as chair and Dr. Daniel Luna (Argentina) as co-chair. The preliminary work of the HI4Dev was to revive its website (http://hi4dev.iosnasean.net) and to build a network of institutions and professionals working in the area of health informatics for development.

With the significant decrease in prices of hardware and the popularity of open source software techniques, there has been tremendous growth in health informatics especially in the developing world. New technologies are emerging (social networking for health) while old ones are diversifying (mHealth). It is the intent of the WG to consolidate these activities in a portal and allow the stakeholders to 
communicate and network with each other for greater and more enhanced collaboration and partnership.

Initially focused on Asia and South America, the WG is intent on expanding to involve Africa and other regions of the world. High on the HI4Dev radar screen are open source electronic health records and culturally-acceptable capability building programs on eHealth and Telemedicine. So far, the HI4Dev has detected and established linkages with eHealth networks in Asia and South America to wit:

The UNDP-International Open Source Network ASEAN+3 (www.iosn.net)

The Centers for eHealth and Telemedicine in Southeast Asia (www.cetsea.net)

PanAsian Collaboration and Networking on eHealth Applications (www.paanceehealth.net)

IMIA LAC

OpenMRS network (www.openmrs.org)

Due to the overlap between development and free and/or open source software, there is tight collaboration right now between the IMIA WG on Open Source and the HI4Dev.

Subsequently, the WG aims to create a network of networks where HI4Dev players contact each other and cooperate in improving health conditions in developing countries through the effective deployment of health informatics.

\section{Objectives:}

- promoting systematic development and research in the field of health information systems

- identifying and assessing problems and success factors of health information systems

- providing intensive feedback between the scientific community, healthcare professionals, and the health IT industry

- facilitating dissemination of industrial solutions and scientific innovations

- supporting sustainable systems, economically, technically and ethically

\section{Recent Activities:}

Most of the energy has been spent to organize a two-day workshop with the theme of "Health Information Systems - 30 Years of Evolution" that will take place just before the Medinfo 2010 Conference in Cape Town.

2010 is a very important date for the IMIA Health Information Systems WG, and Cape Town a very special place:

In 1979 the first HIS working conference was held in Cape Town South Africa. As a result of that conference the International Medical Informatics Association (IMIA) created a working group on hospital information systems. That working group organized a series of working conferences (Nijmegen, Gottingen, Durham, Heidelberg) of which the proceedings have been published.

The next World congress on Medical Informatics, Medinfo, will take place Sept 2010 in Cape Town. This offers a unique opportunity to have another HIS working conference in conjunction with Medinfo where the evolution over a 30year period can be discussed and challenges for the coming decade identified.

At Medinfo several of the pioneers in this field will be present together with new talent. The two-day conference will have 3 plenary sessions and the outcome of the conference will be reported during a panel at Medinfo.

Support has been obtained from Medinfo SPC and LOC, as well as from Prof Reinhold Haux to publish the proceedings in "Methods of Information in Medicine"

Tentative Scientific Program Committee

Marion Ball (USA)

Kiyomu Ishikawa (Japan)

Christian Lovis (Switzerland)

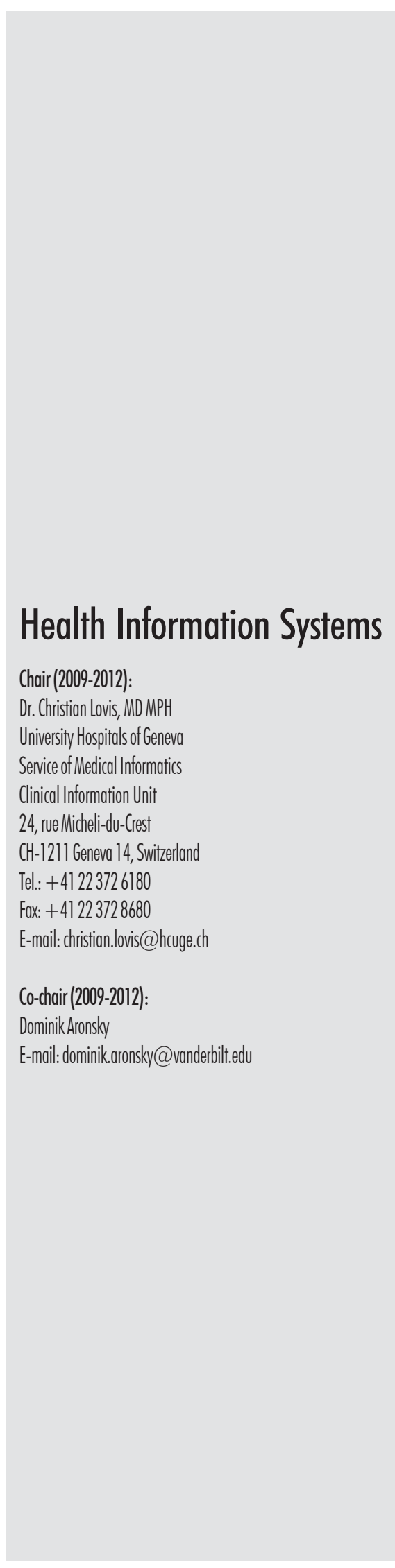

IMIA Yearbook of Medical Informatics 2010 
Otto Rienhoff

Hans Peterson (Sweden)

John Tresling (South Africa)

Ab Bakker (The Netherlands)

\section{Future Activities:}

A two-day workshop with the theme of "Health Information Systems - 30 Years of Evolution" will take place just before the Medinfo 2010 Conference in Cape Town.

\section{Objectives:}

- To promote methods and techniques devoted to the study of human factors in the field of Biomedical Informatics.

- To coordinate studies and actions in this particular domain and to develop standardization initiatives for usability studies and user-centered design in the healthcare domain. This international group of experts will confront state of the art methods, models, innovations and results.

- To disseminate rigorous scientific principles for performing formal usability evaluations to improve their degree of efficiency, acceptability and safety of health informatics applications.

- To support emerging teams in this field in Europe and Northern America: an IMIA Working group will be the opportunity for newcomers to benefit of the support of experts in this domain

\section{Focus:}

Human factors can be the difference between systems that function well in the clinical environment and systems that function poorly. The Physician-Patient relationship has now become the Physician-Computer-Patient relationship. Human factors engineering is the field of study which deals with the cognitive aspects of the human computer interaction. This working group will discuss methods for studying the computer-human interaction in health. New research and methods are needed to evaluate the complex systems facing both clinicians and patients today. Further, this proposed working group will engage in discussions regarding optimal interface designs for health informatics software to make the computer a welcome partner with both the clinician and the patient in the empowered longitudinal care of the individual.

\section{Recent Activities:}

We held a working group meeting in the Netherlands in Amsterdam on December $18^{\text {th }}$ and $19^{\text {th }}$ of 2008 . The scientific program chair for the meeting was Monique Jaspers. We held a masters class in conjunction with the scientific program. The program was well attended and very well received.

\section{Future Activities:}

Our next meeting is being held in Sonoma, California on November $12^{\text {th }}$ and $13^{\text {th }}$. We expect an international set of colleagues. We have had large number of abstracts submitted to the meeting and they are currently being reviewed. The Keynotes are being given by Vimla Patel, PhD and Dag Svanaes from Norway. We expect this to be a stimulating and fun meeting. http://lbi.mssm.edu:8080/HFE2009/main.html

The working group will develop a research agenda for human factors in health informatics. This work will lead to a white paper by the end of year four. 


\section{Objectives:}

Opportunities arise within the discipline of biomedical informatics to facilitate the advancement of genomic and individualized medicine. To effectively link the genotype and phenotype a bi-directional flow of data, tools and methods between two traditionally separate areas of informatics (clinical informatics and bioinformatics) must be ensured.

These interests include, but are not limited to:

- Integrating molecular and genomic information (genetic testing, mutation analysis, gene and protein expression) into health information systems and tools (electronic health records, computerized protocols and clinical guidelines, clinical trials in the context of pharmacogenetics, molecular imaging)

- Generating structured, standardized, anonymous clinical data sets (phenomic data) to be used in the context of post-genomic research (for annotation and validation of experimental results)

- Facilitating new approaches for the integration and analysis of different levels of information (molecular, cellular, tissue, organ, patient, population) about diseases (grid, biobanks, disease modeling and simulation, mapping of clinical and genetic databases and ontologies)

The IGM WG aims to:

- Provide a forum to enhance collaboration, share experiences, and promote research in this field

- Increase communication with other working groups at IMIA, AMIA and other organizations relevant to IGM including groups with an emphasis on genomic medicine and informatics from the biomedical community, computing research and bioinformatics as relevant

- Establish itself as a scientific reference on issues related to information technology projects in genomic medicine

\section{Recent Activities:}

Along the last months we have explored the field of Convergent Technologies (NBIC), their applications in health and the potential links of Biomedical Informatics with new trends in biomedical research (Regenerative, Nanomedicine). As a result of this, two members of the WG wrote a review article for the Yearbook of Medical Informatics and there has been a growth in the number of communications to congresses and articles in relation with the new discipline of medical nanoinformatics.

We have also tried to highlight the importance of connecting the Nano/Bio and Medical informatics developments through the inclusion of these topics within the scientific program of several conferences and in the scope of scientific Journals. Madrid. March 16, 2009.

\section{Future Activities:}

- Coordination of the II International Symposium on Research in Bio/Medical Informatics. Barcelona. 30 October 2009. With the support of SEIS, EFMI and IMIA.

- Publication of the new web page.

- Invited review article on Nanoinformatics for a medical Journal.

- To formalize relationship with the AMIA GEN-WG (Genomics)

- To consolidate a web 2.0 (social networks, blog) community of scientists interested in the application of Informatics to facilitate individualised healthcare

- To set up collaborative information services and tools (Wiki, mailing list, forum)

- To start conversations with other relevant stakeholders in Biomedical Informatics (ISCB, HL7)

\section{Informatics in Genomic Medicine (IGM)}

\author{
Chair(2007-2010): \\ Dr. Fernando J. Martin-Sanchez, PhD \\ Head of the Medical Bioinformatics Department \\ National Institute of Health 'Carlos III', Majadahonda, Madrid \\ Spain \\ Tel: +34918223219 \\ Fax: + 34918223259 \\ E-mail:fms@isciii.es \\ Co-chair(2007-2010): \\ Peter Tarcy-Hornoch, M.D. \\ Head, Division of Biomedical and Health Informatics \\ University of Washington, Seattle WA, USA \\ Tel: +12066858093 \\ Fax: +12065433461 \\ E-mail: pth@u.washington.edu
}

Website: http://www.imia.org ( $\rightarrow$ WGs $\rightarrow$ IGM) 


\section{Medical Concept Representation}

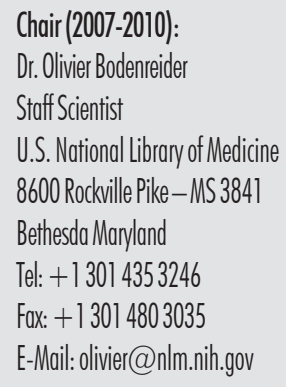

\section{Objectives:}

- To increase the awareness and acceptance of intelligent data analysis and data mining methods in medical community

- To provide an umbrella for scientific discussion and dissemination of new knowledge on data-mining and AI-based methods for data analysis and data mining techniques applied to medicine

- To promote the development of the standardized platforms and solutions

- To provide a forum for presentation of successful intelligent data analysis and data mining implementations in medicine, and discussion of best practices in introduction of these techniques in medical and health-care information and decision support systems

\section{Recent Activities:}

IDADM Working Group is closely collaborating with Knowledge Discovery and Data Mining (KDDM-WG) of AMIA. The Knowledge Discovery and Data Mining Working Group of the American Medical Information Association (AMIA) is announcing its second annual data mining competition for the purpose of studying best practices related to knowledge discovery in health care data. This year's data set is the National Health and Nutrition Examination Survey (NHANES). This is a juried, international data mining competition open to students of any subject or discipline. Four winning individuals or teams will be invited to present their results at the AMIA 2008 Annual Symposium. (No funds for travel or Symposium registration will be provided). Final submissions for the competition are due to the moderator by midnight, September 15, 2008, MDT. Winners of the contest will be invited to present their work at the AMIA Annual Symposium in a panel sponsored by the Knowledge Discovery and Data Mining Working Group. Winners will be selected and recognized by an international panel of judges associated with the KDDM-WG.

\section{Objectives:}

To provide a forum for state of the art dialogue and collaboration on natural language processing and concept representation in healthcare applications, IMIA's Medical Concept Representation Working Group is the international forum for issues related to informatics in the classification and coding of health data. The working group is charged with:

- Reviewing health data nomenclature and classification needs for the world community

- Evaluating information processing technology in meeting these defined needs; and

- Recommending methods for future classification and nomenclature systems

Recent Activities:

- No meeting this year

\section{Future Activities:}

- A WG symposium is planned during the MEDINFO 2010. 


\section{Goals and Objectives:}

Background: The MHWG of IMIA has been in existence since 2000. For a variety of reasons, the Work Group has not been able to garner the resources to achieve its mission.

During this time, the world of informatics in mental health has exponentially changed. Now consumers can use the web for actual therapy. Clinicians can peek into functioning of the brain during cognitive tasks. They search for evidencebased information while taking care of patients. Patients can be seen by there clinicians via tele-psychiatry. Yet, we have not developed ways that informatics can reduce the disease burden of psychiatric disorders, increase collaboration between medical and mental health clinicians, or shared best practices in research, practice, or policy. If an international body can make a difference, it should be in transforming the burden of mental health disorders worldwide and being an international best practices exchange group.

There exist today unlike three years ago, a critical mass of informatics innovators who function as researchers, developers, and policy leaders who have no forum to share perspectives and shape the future of mental health informatics.

IMIA has already multiple corporate, academic, and governmental partners. The Mental Health Workgroup membership should be recruit members from existing partners. As a potential Mental Health Workgroup Chair I propose four goals to be achieved by 2009:

- Formal collaboration with the WHO mental health initiative

- An Annual Publication of International Best Practices in research, policy and practice in collaboration with Elsevier

- An Informatics Policy Framework that would allow medical and mental health clinicians to share information to the betterment of patients and society while protecting confidentiality and privacy

- Corporate, Foundation, and Governmental Support to fund the functions of the IMIA Workgroup

\section{Recent Activities:}

The MH Workgroup is focusing on one goal this year. We hope to publish the first ever paper by this workgroup on the use of self-directed computerized therapy. This is one technology that has international acceptance, and is one of the few technologies that can help reduce disease burden, disability, increase quality, while reducing costs. However, many national policymakers are unaware of their existence or how to implement them in an appropriate manner. The Work Group plans to publish this document by the end of this year, and will have a workshop at the meeting in 2010. The Whitepaper will address anxiety, depression, addiction, stress, and chronic disease.

The MH Workgroup has no funds to pay for travel, secretarial support, or any other expenses. In this international recession, support for a face to face meeting for planning or expert consensus is unavailable. Once this recessions passes, funds should be used for convening mental health informatics experts to address how technology can be used to reduce mental health disease burden internationally.

\section{Mental Health Informatics}

Chair(2006-2009):
Naakesh A. Dewan, M.D.
President
American Association for Technology in Psychiatry
Advanced Psychiatry, P.A.
Center for Mental Healthcare Improvement
2519 N. McMullen Booth Road, Suite 510-255
Clearwater, Fl33761
Tel:+1727 7230779
Fax: + 17277230770
E-mail: drdewan@advancedpsychiatry.com
Co-chair (2007-2010):
Dr. Kannan Subramanian
Managing Director
Kangela Limited
Auckland, New Zealand
Tel: + 6421804414
Fax: +61 280808181
Email: Kangela@xxtra.co.nz




\section{Open Source Health Informatics}

\author{
Chair (2008-2011): \\ Thomas Karopka \\ E-mail:tkaropka@googlemail.com \\ Website: hittp://www.chirad.info/imiaoswg/
}

\section{Objectives:}

The objectives of the group as developed at its formation in 2002 remain relevant, and the focus of the group remains on educational, promotional and 'evangelistic' activities to raise awareness of open source software. While the group is named 'open source', our areas of interest include free/libre software and open source software (as described at in the European Commission-funded FLOSS project see http://www.infonomics.nl/FLOSS/index.htm), and including GNU/Linux.

The objectives of the group are:

- To provide a forum for discussion and for a collaborative, non-judgemental work environment to explore, and where appropriate promote and facilitate, the application of free/libre and open source solutions within health, healthcare and health informatics.

- To bring together experts and interested individuals from a wide range of health professions and with a range of interests in the potential application of free/ libre and open source solutions within their domains of expertise.

- To explore the implications of the free/libre and open source approaches for all aspects of IMIA's areas of interest.

- To work with other IMIA Working and Special Interest Groups to explore the appropriate use of free/libre and open source solutions and applications.

- To facilitate both the use of other groups' expertise in the areas under consideration, and the input of IMIA views to those other groups' work and discussions.

\section{Recent Activities:}

In January we organized a workshop (Open source in European health care - The time is ripe) in Porto, Portugal, in conjunction with the BIOSTEC conference and the EFMI LIFOSS WG. This workshop was very successful and triggered a series of follow-up activities. Since I am also chair of the EFMI LIFOSS WG several activities are in cooperation with this WG.

In April we organized a workshop at Med-e-Tel 2009 called "Sustainable Collaborations in Health Care Open Source Software". At MIE2009 a workshop called "Open Source and Healthcare in Europe - Time to Put Leading Edge Ideas Into Practice" was organized and we submitted a paper with the same title.

Whereas in the EFMI LIFOSS WG we focus on issues in a European context, in the IMIA OS WG we aim to address topics that are interesting on a worldwide level. In the IMIA OS WG we would like to support activities in all parts of the world. Since the WG does not have the means to this we are focusing on networking to support the aims of the WG. Our main activities are dissemination activities concerning FLOSS in health care and the organization of 2-3 workshops/year in conjunction with other groups. We consider IMIA OS WG as the central node in a worldwide network of regional networks/groups/projects that are working in a local context. IMIA OS WG tries to support these local activities and helps to establish links between these different groups.

Our aim in the near future is to have at least one partner-group on every continent. For Europe this is the EFMI LIFOSS WG for North America we have to establish links to the AMIA open source WG, for ASIA this could be a group from APAMI or any other local group dedicated to FLOSS in health care.

\section{Future Activities:}

Since Open source has a great potential for developing countries we will work close together with the IMIA HI4Dev WG in future activities.

We have submitted a Workshop proposal for MEDINFO 2010 "Free/Libre Open Source Software - Prospects, Challenges and Barriers in Healthcare IT". 
IMIA OS WG coorganizes "The Second International Workshop on Open Source in European Health Care: Crossing the Borders - OSEHC 2010", 22 - 23 January, 2010 - Valencia, Spain.

We support the "International Workshop on eHealth in Emerging Economies IWEEE 2010" that will take place in Las Palmas de Gran Canaria, 10-12th of February 2010.

\section{Objectives:}

- To investigate and evaluate organizational, social, ethical, and individual behavioral issues surrounding the introduction and use of informatics applications.

- To determine strategies for systems and workflow analysis, product design and implementation, and technological and organizational change to support health care delivery through information and communication technologies.

- To incorporate organizational change management and human concerns into information technology projects.

\section{Recent Activities:}

\section{CONFERENCE ACTIVITIES}

1. Co-sponsor of a workshop at the ACM Conference on Computer-Supported Collaborative Work titled "CSCW Research on Healthcare: Past, Present, and Future." The conference will be held Feb. 6-10, 2010 in Savannah, GA., USA. OUTREACH and COLLABORATIVE ACTIVITIES

To raise awareness of organizational and social issues in health care, the chair 1 . is serving as a lead editor for a Special Issue of the International Journal of Medical Informatics on "Supporting Collaboration in Healthcare Settings". The publish date is 2010 .

2 . is serving on the steering committee for the Workshop on Interactive Systems in Healthcare to be held at the ACM Conference on Human Factors in Computing (CHI 2010) at Atlanta, GA, April 11, 2010.

3 . is the co-chair of the technical program committee for the ACM Conference on Supporting Group Work. Sanibel Island, Fl, USA, November, 2010.

4. Served as Associate Chair, Program Committee. ACM Conference On Computer Supported Cooperative Work 2010 (CSCW'10). Savannah, GA. Feb 6-10, 2010.

5. Will be the invited speaker at the University of Michigan Health Informatics Grand Rounds. Ann Arbor, MI, December 10, 2009.

6. Was a keynote speaker at the SIG-HEALTH Workshop held at the Americas Conference on Information Systems (AMCIS 2009). San Francisco, CA. August 6, 2009. The title of the talk was Publishing in Medical Informatics Journals: The Interdisciplinary Challenges

\section{On-going Adtivities:}

1. Nominate papers for the Diana Forsythe Award of the AMIA People and Organizational Issues WG.

2. Co-sponsoring a Special Issue of the Journal of Association of Information Systems (JAIS) on "Health Care IT...Process, People, and Patients." The publish date is 2010 .

3. Co-Sponsoring for a Special Issue of the International Journal of Medical Informatics on "Supporting Collaboration in Healthcare Settings". The publish date is 2010 .

4. Co-sponsor AMIA People \& Organizational Issues WG Doctoral Symposium

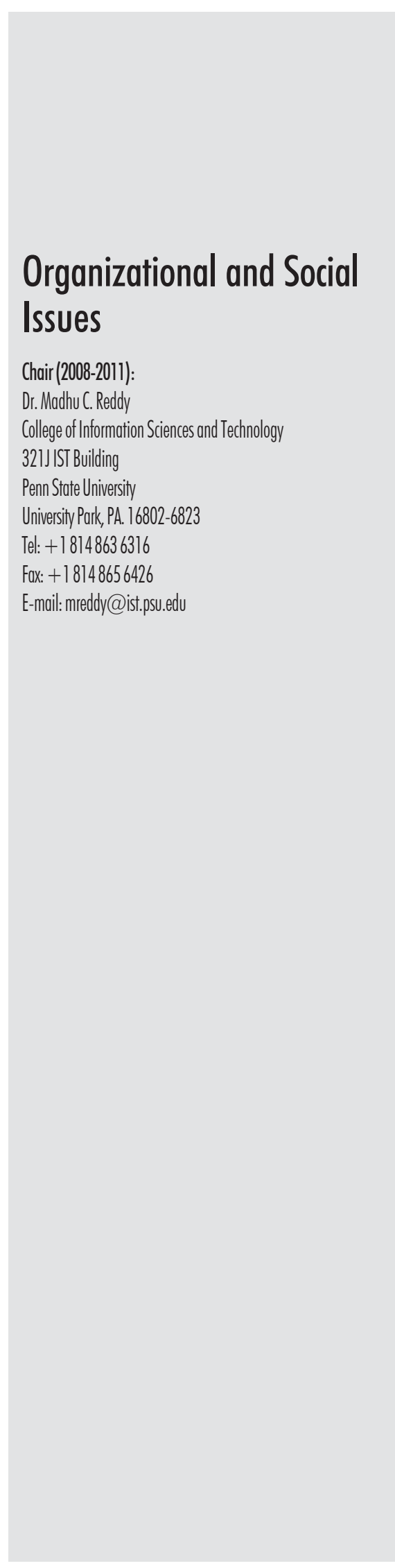

IMIA Yearbook of Medical Informatics 2010 


\section{Primary Health Care Informatics}

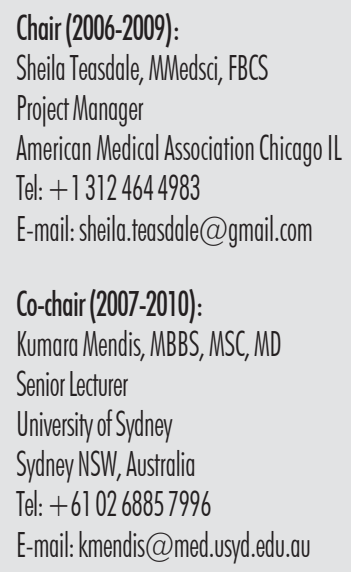

\section{Security in Health Information Systems}

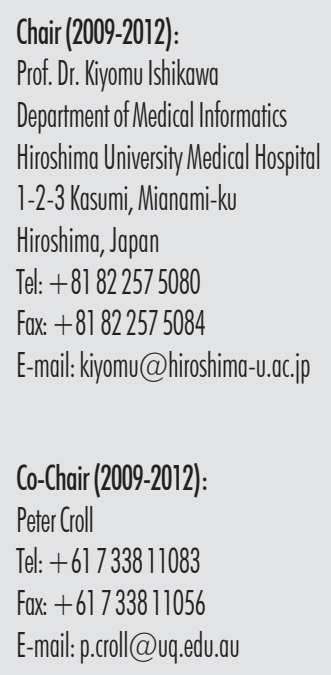

IMIA Yearbook of Medical Informatics 2010

\section{Objectives:}

To promote primary care informatics by:

- acting as a forum for exchange of ideas between WG members

- Providing information to its members to assist them in progressing primary care informatics in their own country

- Increasing the understanding of primary care informatics issues with a view to publishing the results of these discussions

\section{Objectives:}

To examine the issues of data protection and security within the health-care environment. The Data Protection in Health Information Systems Working Group addresses state-of-the-art security of distributed electronic patient records (EPR).

\section{Recent Activities:}

Dr. Ishikawa (Co-chair of SiHIS WG) is going to host WG4 meeting at Hiroshima from November 21 through 24, 2009 where and when JCMI 2009 and APAMI 2009 are going to be held.

We have made the specific programs for the upcoming working conference in Hiroshima.

The focus will be "Trustworthiness of health information - Issues in security and system management for patient safety -". The working conference is promoted by Chair: Dr Kiyomu Ishikawa (Hiroshima Univ.), SPC chair: Dr Koji Yamamoto (Suzuka Univ. of Medical Science), Co-chair: Dr Francois A. Allaert (Univ. of Liege), and Dr Yoshiyasu Okuhara (Kochi Univ.) for the chair of organizing committee.

The summarized session will be scheduled by Prof. Dr Peter Croll (Southern Cross Univ.) and Prof. Dr Eike Kluge (Victoria Univ.) and Bernd Blobel(Regens Burg Univ.), Pekka Ruotsalainen (Kuopo Univ.), Dr Vimla L Patel (Arizona State Univ.) and other core members. 


\section{Goals and Objectives:}

The aim of this working group is the study and promotion of research and development in the area of smart homes and ambient assisted living applications. A "smart home" is a residential setting equipped with a set of advanced electronics, sensors and automated devices specifically designed for care delivery, remote monitoring, early detection of problems or emergency cases and promotion of residential safety and quality of life. Information and Communication Technologies (ICTs) are utilized to allow individuals to live independently in their preferred environment. Thus, systems are patient-centered rather than institution-centered as they are designed to address the needs of individuals, their families and caregivers rather than these of health care facilities. Furthermore, such technologies can allow for the detection of emergencies and provide the means to increase social interaction and minimize isolation for residents (by increasing access to information, entertainment resources and communication with peers). The Working Group provides a forum for ongoing discussion and a collaborative platform for research and development combining expertise in engineering, sensor technologies, ubiquitous computing, health systems, gerontology and human computer interaction. We will address not only technical challenges but also the end users' needs, ethical, clinical and policy issues and the design of sustainable and non-obtrusive interventions, providing a holistic examination of the current status and future trends in smart homes and ambient assisted living.

\section{Recent/Planned Activities:}

\section{Conferences/ Events:}

- The IMIA WG on Smart Homes and Ambient Assisted Living co-sponsored a one day event entitled Forum on Technology and Design for Healthy Aging: What You Can Do now, which took place on May 28, 2009 in Seattle, USA. The University of Washington Institute on Aging was the organizer of this event.

- The IMIA WG on Smart Homes and Ambient Assisted Living was featured as part of a presentation on smart homes during the $31^{\text {st }}$ Annual International Conference of the IEEE Engineering in Medicine and Biology Society in Minneapolis, MN, USA in September 2009.

- The IMIA WG on Smart Homes and Ambient Assisted Living is co-sponsoring the Symposium on Technology Tools to support Older Adults' Social Interactions and Independence to be held November $21^{\text {st }}$, during the Gerontological Society of America (GSA) 62 ${ }^{\text {nd }}$ Annual Scientific Meeting in Atlanta, Georgia, US.

\section{Smart Home Registry:}

We have created a registry of ongoing smart home and ambient assisted living projects. This registry currently includes 22 entries (i.e., 22 existing ongoing smart home projects), however we plan on continuing to invite researchers and designers through our website and listserv as well as individual members' professional networks to register their projects with our database to allow for a comprehensive assessment of ongoing efforts worldwide as well as for identification of collaboration opportunities.

\section{Working Group Website:}

The WG website was created in December 2006. The site is at http://www.healthsmarthomes.org/

The site includes information about existing research projects and other related resources, as well as links to related organizations, announcements and events. It is being updated regularly.

\section{Working Group Listserv:}

The WG listserv smarthomes@u.washington.edu was established in December 2006 and at the time of writing this report, it includes 218 members.

\section{Next Steps:}

We continue to update and expand the registry of ongoing smart home and ambient assisted living projects. We will continue to promote dissemination of the working group members' work with theme issues, workshops and tutorials. Finally, we plan on organizing a special topic conference focusing on the WG areas.

\section{Smart Homes and Ambient Assisted Living}

Chair:

Dr. George Demiris, PhD

Associate Professor

Biomedical and Health Informatics, School of Medicine \&

Biobehavioral Nursing and Health Systems, School of Nursing

University of Washington, Seattle, WA, USA

E-mail:gdemiris@u.washington.edu

Website: http://www.health-smarthomes.org/ 


\section{Standards in Health Care Informatics}

\author{
Chair(2008-2011): \\ Kai Heitmann \\ E-mail:hl7@kheitmann.nl \\ Website: htrp://mi.hama-med.ac.jp/stds/index-en.html
}

\section{Technology Assessment \& Quality Development in Health Informatics}

\author{
Chair (2008-2010): \\ Nicolette de Keizer \\ Dept. of Medical Informatics \\ Academic Medical Center \\ Meibergdreef 15, 1105 AZAmsterdam \\ The Netherlands \\ Tel: + 31205665205 \\ E-mail:n.f.keizer@amc.uva.nl
}

\section{Objectives:}

- To advise about standards from an academic perspective

- To promote the mutual identification of needed standards world-wide

- To share information to facilitate mutual coordination of standards development in health informatics

Expanded description of the content areas that will be worked on by the Working Group

- WG 16 itself does not create new standards; rather, it devotes its activity on promotion of mutual identification and coordination by posting and maintaining an inventory of health informatics standard activities.

- Usually, standard development activities are by volunteers, vendors, and immediate users. It is quite natural and fine for them to devote efforts to acquire fruitful outcomes. Sometimes, however, potential future users' profit could be underrated.

- IMIA is academically oriented, and is a world-wide organization which has connections with countries which participate less currently in existing standard development activities.

- Therefore, IMIA WG 16 inputs thoughtfulness for future users and for multicultural environments, as advisory to standard development activities.

\section{Recent Activities:}

IMIA WG16 for standards has been organizing annual workshops at the time of international MI conferences, such as MEDNIFO 2007, APAMI 2006, MIE 2005, etc. Also it continues to contribute to ISO/TC215 (Health Informatics) as type D liaison.

\section{Future Adtivities:}

Planned event is in Hiroshima in conjunction with the JCMI 2009 and the APAMI 2009 late November.

\section{Recent Activities:}

- After publishing STARE-HI, the Statement for Reporting on Evaluation Studies in Health Informatics (Int J Med Inform 2009; 78(1)), WG members are now working on

o miniSTARE-HI for proceedings papers; this work is lead by Nicolette de Keizer, Amsterdam; and

0 an Explanatory paper elaborating and discussing details in the STARE-HI guidelines; this work is lead by Jytte Brender, Aalborg together with Jan Talmon, Maastricht.

- The Working Group has finalized a draft of the Good Evaluation Practice Guidelines in Health Informatics (GEP-HI). Those guidelines describe the activities and actors of an IT evaluation study in health informatics. This work is lead by Pirkko Nykanen, Tampere, together with Jytte Brender, Aalborg. Working documents on GEP-HI can be found at http://iig.umit.at/efmi.

- The WG organized a workshop on "GEP-HI: Introducing guidelines for good evaluation practice in health informatics" at MIE 2009, Aug30-Sept2 2009, Sarajevo.

- Another workshop on "GEP-HI: Good evaluation practice guidelines in health informatics" at AMIA 2009 in San Francisco, Nov14 - 182009 was organized in close cooperation with the IMIA WG on Technology Assessment.

- The WG organizes three workshops (on STARE-HI, miniSTARE-HI, and GEPHI) at Medinfo 2010, September 2010, Cape Town. 
- Further (selected) publications related to core work of the WG:

o Rigby M et al. Planning to test success - Employing the guidelines for Good Evaluation Practice in Health Informatics (GEP-HI). In: Proceedings of eHealth 2009 (EH 2009), pp. 209 - 213.

0 Rigby Michael et al. Linking Informaticians and End Users - Using the STAREHI Evaluation Reporting Framework as a Unifying Design Approach. In: Proceedings of MIE 2009. pp. 66-70.

o Nykänen Pirkko et al. Introducing guidelines for good evaluation practice in health informatics. In: Proceedings of MIE 2009. pp. 958-62.

- The WG has been involved in the Alliance for Clinical Excellence (ACE), a key global initiative which was formed in response to a growing global demand in the healthcare industry for predictive, evidence-based metrics to determine the costand-benefit equation of IT in Healthcare.

- The web-based Evaluation Inventory was completely updated and expanded. It now comprises around 1.500 abstracts of evaluation papers in health informatics and allows researchers from all over the world to submit papers for inclusions. The Evaluation Inventory database is available for free at http://evaldb.umit.at. This work is lead by Elske Ammenwerth and Nicolette de Keizer.

- As the IMIA WG closely collaborates with the EFMI WG we share a mailing list (comprising at the moment 280 members) and a website at http://iig.umit.at/efmi/ . This website presents the ongoing activities and working documents of the groups. Elske Ammenwerth is in lead to maintain this mailing list and website.

- In all listed activities, the IMIA WG on Technology Assessment closely collaborates with EFMI WG on Evaluation lead by prof. dr. E Ammenwerth (chair)

\section{Future Activities:}

- Finalise the GEP-HI paper.

- Adaption of STARE-HI for specific types of evaluation studies such as Human Factor Engineering and Evaluation.

- Extend the Medinfo paper on STARE-HI for conference papers to full paper.

- Start a validation assessment of STARE-HI to assess quality of evaluation papers

- Workshops on evaluation methodology at MIE, MEDINFO and AMIA conferences

- Exploration of other directions of Quality Development

- Further exploration of cooperation with ACE

\section{Objectives:}

- To explore the rationale and perspective of Health Telematics

- To promote the design and development of open architecture and interoperability tools

- To promote the analysis, design and development of methodologies and applications to support collaborative work in healthcare information systems

- To share experiences on E-health, Telemedicine and Professional Healthcare networks

\section{Telematics in Health Care}

Chair(2008-2011):

Dr. Knut Bernstein

Consultant MEDIQ - Medical Informatics and Quality Development

Bronshoi, Copenhagen

Denmark

Tel: +4530922272

E-mail:kb@mediq.dk 